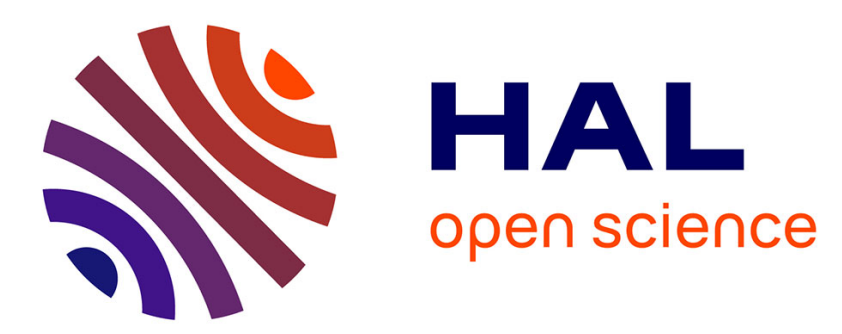

\title{
From diluted solid solutions to high entropy alloys: Saturation grain size and mechanical properties after high pressure torsion
}

\author{
Tom Keil, Enrico Bruder, Mathilde Laurent-Brocq, Karsten Durst
}

\section{- To cite this version:}

Tom Keil, Enrico Bruder, Mathilde Laurent-Brocq, Karsten Durst. From diluted solid solutions to high entropy alloys: Saturation grain size and mechanical properties after high pressure torsion. Scripta Materialia, 2021, 192, pp.43-48. 10.1016/j.scriptamat.2020.09.046 . hal-03450631

\section{HAL Id: hal-03450631 \\ https://hal.science/hal-03450631}

Submitted on 26 Nov 2021

HAL is a multi-disciplinary open access archive for the deposit and dissemination of scientific research documents, whether they are published or not. The documents may come from teaching and research institutions in France or abroad, or from public or private research centers.
L'archive ouverte pluridisciplinaire $\mathbf{H A L}$, est destinée au dépôt et à la diffusion de documents scientifiques de niveau recherche, publiés ou non, émanant des établissements d'enseignement et de recherche français ou étrangers, des laboratoires publics ou privés. 
Keil, T., Bruder, E., Laurent-Brocq, M., and Durst, K., From diluted solid solutions to high entropy alloys: Saturation grain size and mechanical properties after high pressure torsion. Scripta Materialia, 2021. 192: p. 43-48. https://doi.org/10.1016/j.scriptamat.2020.09.046

1 From diluted solid solutions to high entropy alloys: Saturation grain size and mechanical

2

3

4

5

6

7

8

9

\section{properties after high pressure torsion}

Tom Keil*a, Enrico Bruder ${ }^{a}$, Mathilde Laurent-Brocq ${ }^{b}$, Karsten Durst ${ }^{a}$

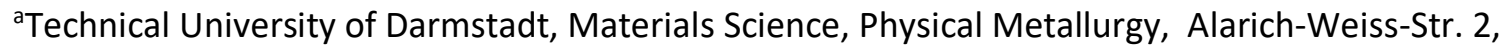
64287 Darmstadt, Germany

bUniversité Paris Est Créteil, CNRS, ICMPE, UMR 7182, Thiais, France

* Corresponding author

Abstract:

Effects of solutes on saturation grain size and mechanical properties are investigated for the Cantor alloy and $\mathrm{Ni}$-enriched variations $\left((\mathrm{CrMnFeCo})_{x} \mathrm{Ni}_{1-\mathrm{x}}\right)$ with $\mathrm{x}=0.8,0.4,0.08$ and 0 . Indentation on coarse-grained and severely deformed states shows increasing hardness with increasing alloying content due to higher solid solution strengthening and Hall-Petch contributions. Nanoindentation strain rate jump tests reveal similar rate sensitivities of the deformed states without pronounced transient regimes. All compositions exhibit a history dependent softening indicating an unstable microstructure. The saturation grain size $d_{s}$ after HPT deformation inversely correlates with the solid solution strengthening contribution, i.e. the higher $\Delta \tau$ the lower $\mathrm{d}_{\mathrm{s}}$.

Keywords: High Entropy Alloy; High pressure torsion; Nanoindentation; Microstructure 
Keil, T., Bruder, E., Laurent-Brocq, M., and Durst, K., From diluted solid solutions to high entropy alloys: Saturation grain size and mechanical properties after high pressure torsion. Scripta Materialia, 2021. 192: p. 43-48. https://doi.org/10.1016/j.scriptamat.2020.09.046

Single-phase high entropy alloys (HEAs), such as the five component equiatomic CrMnFeCoNi Cantor alloy [1] have attracted a wide research interest in recent years. The concept of HEAs opens up a high number of possible alloys, with compositions placed in the centre of the multicomponent phase diagram. Given the large number of possible alloy systems, only a few alloys form a single-phase solid solution [2-4] and the Cantor alloy is one of them. However, it is still unclear how the properties change, starting from diluted solid solutions to a HEA [5]. Therefore, Laurent-Brocq et al. [5, 6] have studied diluted subsystems of the Cantor alloy along various isopleths and discovered a breakpoint of the lattice parameter and hardness evolution for Ni-enriched alloys at 40 at.\% solute concentration, where a transition between diluted systems and high entropy alloy takes place.

The Ni-diluted Cantor systems are therefore nicely suited to study the influence of solid solution strengthening effects on the grain refinement during severe plastic deformation and the resulting properties of the ultrafine-grained (UFG) or nanocrystalline (NC) HEA. We use diluted subsystems of the Cantor alloy - starting from pure $\mathrm{Ni}$ to the five-component Cantor alloy - to understand the transition from conventional alloys to HEAs in terms of solid solution strengthening effects and mechanical properties (i.e. effect of grain boundaries, stain rate sensitivity).

One common method to achieve high defect densities in the microstructure and to reduce the grain size to the UFG or NC regime is high pressure torsion (HPT) [7], which has already been applied to the Cantor system [8, 9]. Even though severe plastic deformation processes have been used for many years, the principle mechanisms of grain refinement and saturation grain size $d_{s}$ (minimum achievable grain size at large strain) are still under debate. The stacking fault energy (SFE) affects the dislocation cell formation and refinement rate, but its influence on the saturation grain size $d_{s}$ is not evident. [10-12] A comparison of pure metals $(\mathrm{Ni}, \mathrm{Cu}, \mathrm{Ag})$ with strongly different SFEs reveals no difference in $d_{s}$ after HPT deformation at given homologous temperature [10]. Recent studies on the influence of SFE and solid solution strengthening (SSS) on $d_{s}$ suggest that it is mainly controlled by the SSS contribution in the alloy system rather than the SFE [11, 12]. Edalati et al. [11] found an empirical correlation between SSS contribution determined by the Labusch model and the minimum achievable grain size for different binary alloys, which can be explained by stronger localized stress fields hindering necessary dislocation motion and thus dislocation recovery, grain boundary 
Keil, T., Bruder, E., Laurent-Brocq, M., and Durst, K., From diluted solid solutions to high entropy alloys: Saturation grain size and mechanical properties after high pressure torsion. Scripta Materialia, 2021. 192: p. 43-48. https://doi.org/10.1016/j.scriptamat.2020.09.046

migration or recrystallization. The resulting dislocation accumulation due to a lower mobility of edge dislocations causes smaller steady-state grain sizes in face-centered cubic (FCC) alloys. This knowledge about defect storage vs. recovery and deformation behavior can now be transferred to chemically complex systems to shed light on SSS processes in HEAs, which have not yet been fully understood. A correlation of the saturation grain size and predicted solid SSS contributions from different strengthening models can be used to investigate these effects in HEAs.

In this work, the influence of solute strengthening on saturation grain size $d_{s}$, hardness and rate sensitivity is investigated for three selected alloys with the nominal compositions $\mathrm{Cr}_{2} \mathrm{Mn}_{2} \mathrm{Fe}_{2} \mathrm{Co}_{2} \mathrm{Ni}_{92}$ (further referred to as $\mathrm{Ni92}$ ), $\mathrm{Cr}_{10} \mathrm{Mn}_{10} \mathrm{Fe}_{10} \mathrm{Co}_{10} \mathrm{Ni}_{60}$ (Ni60), the equiatomic $\mathrm{Cr}_{20} \mathrm{Mn}_{20} \mathrm{Fe}_{20} \mathrm{CO}_{20} \mathrm{Ni}_{20}$ (Ni20) Cantor alloy as well as for pure $\mathrm{Ni}(\mathrm{Ni100})$ as a reference material with minor solute strengthening effects. The Ni reference sample has a purity of $99.6 \%$. After homogenization, Ni92, $\mathrm{Ni60}$ and $\mathrm{Ni20}$ exhibit compositions of $\mathrm{Cr}_{2.5} \mathrm{Mn}_{2.4} \mathrm{Fe}_{2.6} \mathrm{Co}_{2.9} \mathrm{Ni}_{89.6}$, $\mathrm{Cr}_{10.5} \mathrm{Mn}_{9.9} \mathrm{Fe}_{10.3} \mathrm{CO}_{10.6} \mathrm{Ni}_{58.7}$ and $\mathrm{Cr}_{20.6} \mathrm{Mn}_{19.3} \mathrm{Fe}_{19.9} \mathrm{Co}_{20.1} \mathrm{Ni}_{20.1}$. The purity levels of the used elements are at least $99.9 \%$ and the production routes are described elsewhere $[13,14]$.

Due to the chemical complexity and the absence of a main matrix element in high entropy systems, the Varvenne model $[15,16]$, which is specifically designed for FCC HEAs, is used to calculate the shear stress $\Delta \tau_{\text {Varvenne }}$ induced by solid solution strengthening. The calculated SSS contribution can also be linked to the predicted yield strength from Varvenne et al. [15] using the Taylor factor of 3.06 for FCC polycrystals. The required material parameters are obtained from Refs. $[17,18]$ using the rule-of-mixtures, the atomic size misfit volumes are taken from Ref. [15], respectively. Here, the calculated shear stress due to SSS differ strongly from $0 \mathrm{MPa}$ for pure Ni up to $41.4 \mathrm{MPa}$ for the Cantor alloy.

Discs with an initial height of $2 \mathrm{~mm}$ were deformed to 10 revolutions at a rate of $1.0 \mathrm{rpm}$ with an applied contact pressure of $5.0 \mathrm{GPa}$ using active water-cooling. Subsequently, the HPT samples were annealed at $900{ }^{\circ} \mathrm{C}$ for $1 \mathrm{~h}$ to achieve a coarse-grained state (CG) of the alloys. Flat sections of the HPT discs were prepared by grounding and polishing down to colloidal silica, hence the loading direction of the nanoindentation system and the viewing direction for microstructural analysis is parallel to the loading direction of the HPT process. Nanoindentation testing was then performed on the CG and the deformed HPT states using a 
Keil, T., Bruder, E., Laurent-Brocq, M., and Durst, K., From diluted solid solutions to high entropy alloys: Saturation grain size and mechanical properties after high pressure torsion. Scripta Materialia, 2021. 192: p. 43-48. https://doi.org/10.1016/j.scriptamat.2020.09.046

G200 nanoindentation system (KLA) with a diamond Berkovich tip (Synton-MDP) on the outer radius of the samples, $1 \mathrm{~mm}$ away from the edge of the sample. The indentation modulus and hardness were measured using a continuous stiffness measurement method (CSM) at an input strain rate of $0.05 \mathrm{~s}^{-1}$ and the rate sensitivity of the different states was investigated by strain rate jump tests (SRJ), where every $500 \mathrm{~nm}$ indentation depth the applied strain rate was varied between $0.05 \mathrm{~s}^{-1}, 0.005 \mathrm{~s}^{-1}$ and $0.001 \mathrm{~s}^{-1}$. The saturation grain size $d_{s}$ was analyzed using a highresolution scanning electron microscope (TESCAN Mira3) in backscattered electron (BSE) contrast imaging mode using a line intercept method. The microstructural characterization was carried out at a distance of $1 \mathrm{~mm}$ from the outer edge of the samples to ensure a homogeneous deformation.

Fig. 1 a) shows the hardness as a function of the indentation depth for the CG states. Here, the hardness decreases with higher indentation depth, which is caused by the indentation size effect (ISE) and can be described well by the Nix-Gao model [19] (dashed lines). According to the Nix-Gao model, the macroscopic hardness $\mathrm{H}_{0}$ can be extracted from nanoindentation data: $\mathrm{H}_{0, \mathrm{Ni} 20}=1.91 \pm 0.11, \mathrm{H}_{0, \mathrm{Ni} 00}=1.88 \pm 0.11, \mathrm{H}_{0, \mathrm{Ni92}}=1.41 \pm 0.16, \mathrm{H}_{0, \mathrm{Ni} 100}=1.08 \pm 0.10$. The macroscopic hardness is only slightly smaller compared to the averaged hardness in the indentation depth interval from $2000-2200 \mathrm{~nm}$ (see Tab. 1), thus the hardness has already reached a depth independent plateau. In order to minimize the influence of the ISE, the hardness and indentation modulus are averaged over an indentation depth interval from $2000-2200 \mathrm{~nm}$ for further analysis. Furthermore, the internal length scale $\mathrm{h} *$ is determined, which describes the dislocation storage capability (sensitivity to strain gradients) of a material [20]. An increasing alloying element content starting from pure Ni to Ni92 decreases $h$ * substantial, a further addition shows only a minor effect on $\mathrm{h}^{*}$ from Ni92 to the equiatomic Cantor alloy (Fig. 1b)).

Nanoindentation of the CG states shows an increasing hardness with increasing alloying content due to stronger SSS and Hall-Petch contributions starting from pure Ni up to the equiatomic Cantor alloy (Ni20) (Fig. 1c)). This superposition is due to the fact that the microstructure is different for the four compositions, which result in deviations of the HallPetch contributions (Ni100: $22.3 \pm 15.5 \mu \mathrm{m}$, Ni92: $11.4 \pm 6.3 \mu \mathrm{m}, \quad N i 60: 13.5 \pm 7.9$ and Ni20: $8.3 \pm 4.2 \mu \mathrm{m})$. Therefore, the hardness increase from Ni100 to Ni20 is caused by an increase of SSS and Hall-Petch contributions, hence, the SSS contribution cannot be derived 
Keil, T., Bruder, E., Laurent-Brocq, M., and Durst, K., From diluted solid solutions to high entropy alloys: Saturation grain size and mechanical properties after high pressure torsion. Scripta Materialia, 2021. 192: p. 43-48. https://doi.org/10.1016/j.scriptamat.2020.09.046

111 from the hardness data. Due to the annealing of the CG states, we expect no differences in 112 the dislocation densities and nearly dislocation-free microstructures for the different 113 compositions as it was shown in Ref. [21] for the Cantor alloy. The present nanoindentation results of the CG states are in good agreement with Laurent-Brocq et al. $[5,6]$ in terms of hardness and modulus, considering a different grain size and indentation depth. The saturated HPT states show the trend of an increasing hardness with increasing alloying content with its maximum for Ni60, for which the SSS contribution is in the range of Ni20 at approximately $40 \mathrm{MPa}$. Although Ni20 shows a slightly higher SSS contribution and smaller grain size, Ni60 has the highest hardness. In literature, higher dislocation densities after HPT deformation are found for the Cantor alloy (Ni20 in the order of $10^{16} \mathrm{~m}^{-2}[22]$ ), in comparison to pure $\mathrm{Ni}$ (Ni100 $10^{15} \mathrm{~m}^{-2}$ [23]). The higher dislocation density for Ni20 could also contribute to the increase in hardness from Ni100 to Ni20. Furthermore, the HPT states show significantly higher hardness ( $\approx 6 \mathrm{GPa}$ ) compared to the $\mathrm{CG}$ states $(\approx 2 \mathrm{GPa})$. The indentation modulus is similar for both microstructural states and thus unaffected by the grain size (Tab. 1).
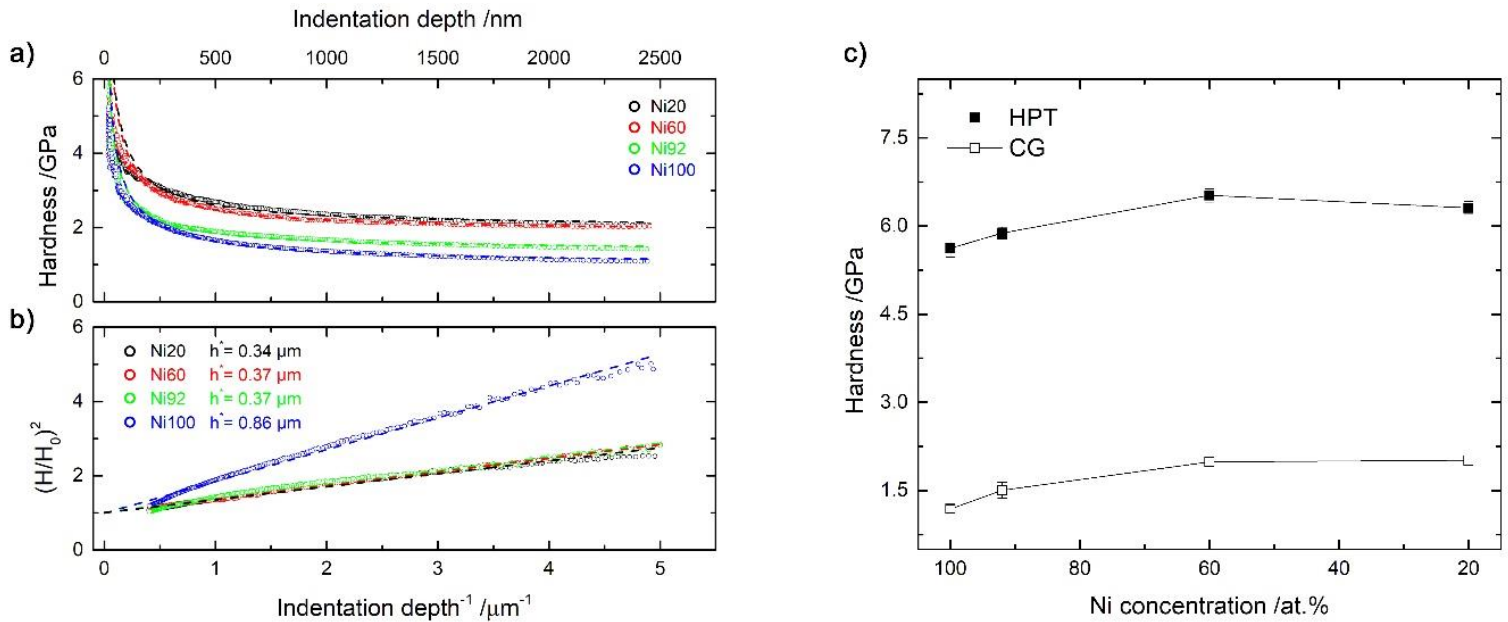

Fig. 1: a) nanoindentation testing of the annealed CG samples (1h at $900{ }^{\circ} \mathrm{C}$ ) at constant strain rate of $0.05 \mathrm{~s}^{-1}$, the dashed lines represent the hardness calculated by the Nix-Gao model, b) Nix-Gao analysis of the CG sample data and c) indentation hardness as a function of composition for the CG and HPT states. Nanoindentation testing data of the HPT samples are shown in Appendix A2.

The strain rate sensitivity, i.e. thermally activated deformation processes of the different alloy systems in the HPT states are investigated using nanoindentation strain rate jump tests (Fig. 2). Whereas in the CG states the hardness decreases with increasing indentation depth (caused by indentation size effect - ISE), the HPT specimens show a nearly depth independent 
Keil, T., Bruder, E., Laurent-Brocq, M., and Durst, K., From diluted solid solutions to high entropy alloys: Saturation grain size and mechanical properties after high pressure torsion. Scripta Materialia, 2021. 192: p. 43-48. https://doi.org/10.1016/j.scriptamat.2020.09.046

hardness at indentation depths greater than $500 \mathrm{~nm}$ (Fig. 2) at a strain rate of $0.05 \mathrm{~s}^{-1}$. The strain rate sensitivity is determined using the strain rate jumps at $1500 \mathrm{~nm}$ indentation depth from $0.05 \mathrm{~s}^{-1}$ to $0.001 \mathrm{~s}^{-1}$ (inset in Fig. 2). Higher strain rates cause higher hardness values for both, the diluted solutions ( $\mathrm{Ni92,} \mathrm{Ni100)}$ as well as the chemically complex alloys (Ni20, Ni60). Additionally, the rate sensitivity in the HPT states $(m \approx 0.01)$ is similar for all compositions. The corresponding activation volumes $\mathrm{V}\left(V=C * \sqrt{3} k_{B} * T / m H\right)$, with $\mathrm{C}$ : constraint factor of 3 , $\mathrm{k}_{\mathrm{B}}$ : Boltzmann constant and $\mathrm{T}$ : room temperature of $25^{\circ} \mathrm{C}$, are in the same range of $19-23 \mathrm{~V}^{*} \mathrm{~b}^{3}$ for the different compositions and confirm the results from Maier-Kiener et al. on NC-Ni $\left(14 \mathrm{~V}^{*} \mathrm{~b}^{3}\right)$ [24] and NC Cantor $\left(16 \mathrm{~V}^{*} \mathrm{~b}^{3}\right)$ [25]. The indentation modulus is not affected by changes in the strain rate, but show stronger scattering in intervals with lower strain rate due to the higher number of data points (Appendix A1), which was previously observed in literature [25].

In FCC materials, the strain rate sensitivity is more pronounced for decreasing grain sizes, as thermally activated dislocation - grain boundary interactions become more dominant due to the higher number of grain boundaries. [26, 27]. After HPT, the different compositions show similar strain rate sensitivities in the range of 0.01 . This implies that the strain rate sensitivity is compositionally independent and is also not affected by grain size differences in the NC or UFG regime, as the different compositions show grain sizes in an interval from approx. $50 \mathrm{~nm}$ (Ni20) to $150 \mathrm{~nm}$ (Ni100).

The present SRJ tests reveal an unstable microstructure of the different alloy systems, as the hardness shows a history dependent behavior $[26,27]$. The hardness plateaus at a strain rate of $0.05 \mathrm{~s}^{-1}$, which are interrupted by a strain rate segment of $0.001 \mathrm{~s}^{-1}$ show a history dependent softening of approx. $1.3-2.0 \%$. This softening is discussed on being linked to grain coarsening processes [12].

Differences in the transient behavior can be observed for the investigated compositions in the enlarged section of Fig. 2 at a strain rate change from $0.05 \mathrm{~s}^{-1}$ to $0.001 \mathrm{~s}^{-1}$. The hardness changes abruptly for all compositions, with a continuous softening for $\mathrm{Ni100}$, whereas $\mathrm{Ni20}$ and Ni60 show after the strain rate jump a short period of strain hardening. This phenomenon has been observed before for the nanocrystalline Cantor alloy [25], and also the more diluted Ni60 composition shows the same effect. This yield point effect is limited to the more 
Keil, T., Bruder, E., Laurent-Brocq, M., and Durst, K., From diluted solid solutions to high entropy alloys: Saturation grain size and mechanical properties after high pressure torsion. Scripta Materialia, 2021. 192: p. 43-48. https://doi.org/10.1016/j.scriptamat.2020.09.046

concentrated Ni20 and Ni60 HEA-type alloys and is almost not observable for Ni92. Moreover, only Ni20 with the lowest grain size of $55 \pm 17 \mathrm{~nm}$ shows serrations in the hardness in the strain rate segment of $0.001 \mathrm{~s}^{-1}$, which is commonly related to dynamic dislocation pinning and breakaway during plastic deformation [21]. For nanomechanical testing, the activation volume represents the number of atoms, which are involved in the thermally activated deformation [28]. In NC materials with low activation volumes, the deformation mechanisms are related to thermally activated diffusion processes at grain boundaries [24], which can be associated to the observed serration behavior at low strain rates.

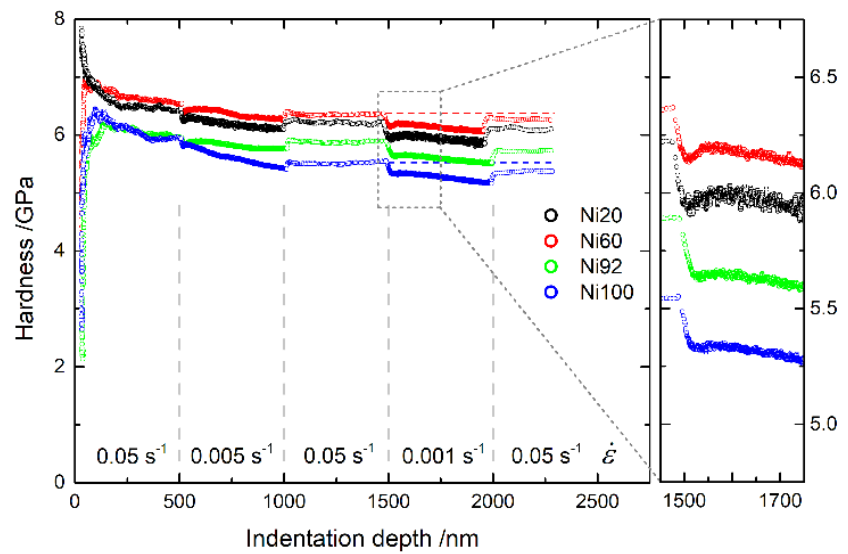

Fig. 2: Nanoindentation strain rate jump tests on Ni-X alloys deformed by HPT.

The saturation grain sizes determined by BSE (Fig. 3) are in good agreement to grain size reference values from literature for $\mathrm{Ni20}$ (50 nm [8]) and $\mathrm{Ni100}$ (170 nm [23]). The evaluation of the minimal achievable grain size (see Tab. 1) reveals that an increasing alloying content and thus a stronger SSS contribution leads to smaller saturation grain sizes from $142 \pm 57 \mathrm{~nm}$ $\left(\mathrm{Ni}_{100}\right)$ to $55 \pm 17 \mathrm{~nm}\left(\mathrm{Ni}_{20}\right)$. We do not expect any significant influence by the presence of impurities in the ingredient elements on the saturation grain size, as changes in the purity level of Ni between $99.5 \%$ and $99.967 \%$ result only in slight changes of the microstructure [29].

The SSS contribution $\tau_{\text {Labusch }}$ is calculated using the equations proposed by Edalati [11] and for the $\tau_{\text {Varvenne }}$ calculation the notation from Ref. [30] is used. Fig. 4 shows the correlation 
Keil, T., Bruder, E., Laurent-Brocq, M., and Durst, K., From diluted solid solutions to high entropy alloys: Saturation grain size and mechanical properties after high pressure torsion. Scripta Materialia, 2021. 192: p. 43-48. https://doi.org/10.1016/j.scriptamat.2020.09.046

between the SSS contribution (Labusch, Varvenne SSS models) and the normalized saturation grain size $\left(d_{s} / b\right)$, with $b$ as the Burgers-vector.

The correlation found by Edalati et al. [11] for binary solutions breaks down for the highly concentrated solid solutions (see Fig. 4). Despite a higher SSS contribution of Ni 20 compared to Ni60 (Labusch), both alloys exhibit nearly the same grain size.

For conventional alloys, the correlation between saturation grain size and SSS contribution can be attributed to stronger localized stress fields and hindered dislocation motion, dislocation recovery and grain boundary migration or recrystallization. Thus, smaller steadystate grain sizes can be achieved [11]. The same processes seem to influence the saturation grain size in FCC medium and high entropy alloys, as the same dependency of saturation grain size on SSS contribution is obtained using the Varvenne SSS model (all data points lie on a single line in a semi-log scale (see Fig. 4)). The Varvenne model predicts the same SSS contribution for $\mathrm{Ni20}$ and Ni60, which is in good agreement with the experimentally observed saturation grain size and hardness that are in the same range for both alloys (see Tab. 1). This is also confirmed by literature, showing a breakpoint in lattice parameter evolution at 60 at.\% $\mathrm{Ni}$, which leads to similar lattice constants for $\mathrm{Ni20}$ and $\mathrm{Ni60}$ [5].

Extrapolating ds using the Labusch model and the saturation grain sizes of $\mathrm{Ni}, \mathrm{Ni92,} \mathrm{Ni60,}$ would lead to a saturation grain size of Cantor of approx. $37 \mathrm{~nm}$. This is still within the experimental scatter bar, however the Varvenne model seems to give a better description.

While we do see a correlation with SSS, we still don't know what the exact mechanism is. However, segregation phenomena (phase decomposition, inhomogeneities or clusters of solutes) due to HPT deformation appear to be unlikely to play a role given that they do not exist in the extreme cases ( $\mathrm{Ni20}[8]$ and $\mathrm{Ni100}$ ) and presumably also not within the entire concentration range even though this remains to be proven experimentally. 
Keil, T., Bruder, E., Laurent-Brocq, M., and Durst, K., From diluted solid solutions to high entropy alloys: Saturation grain size and mechanical properties after high pressure torsion. Scripta Materialia, 2021. 192: p. 43-48. https://doi.org/10.1016/j.scriptamat.2020.09.046
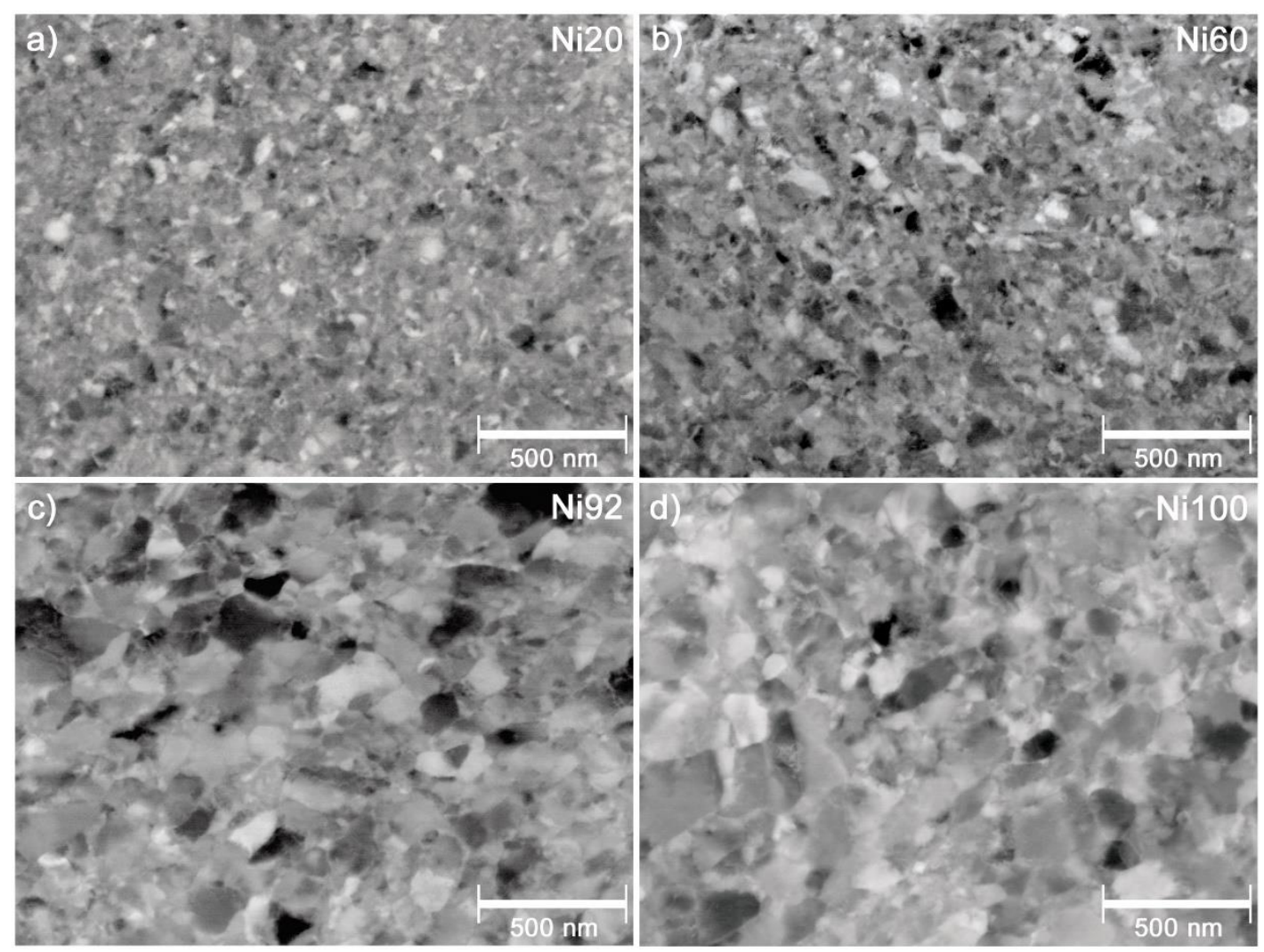

Fig. 3: BSE images of the different alloy systems after HPT deformation: a) Ni20, b) Ni60, c) Ni92 and d) Ni100. 
Keil, T., Bruder, E., Laurent-Brocq, M., and Durst, K., From diluted solid solutions to high entropy alloys: Saturation grain size and mechanical properties after high pressure torsion. Scripta Materialia, 2021. 192: p. 43-48. https://doi.org/10.1016/j.scriptamat.2020.09.046

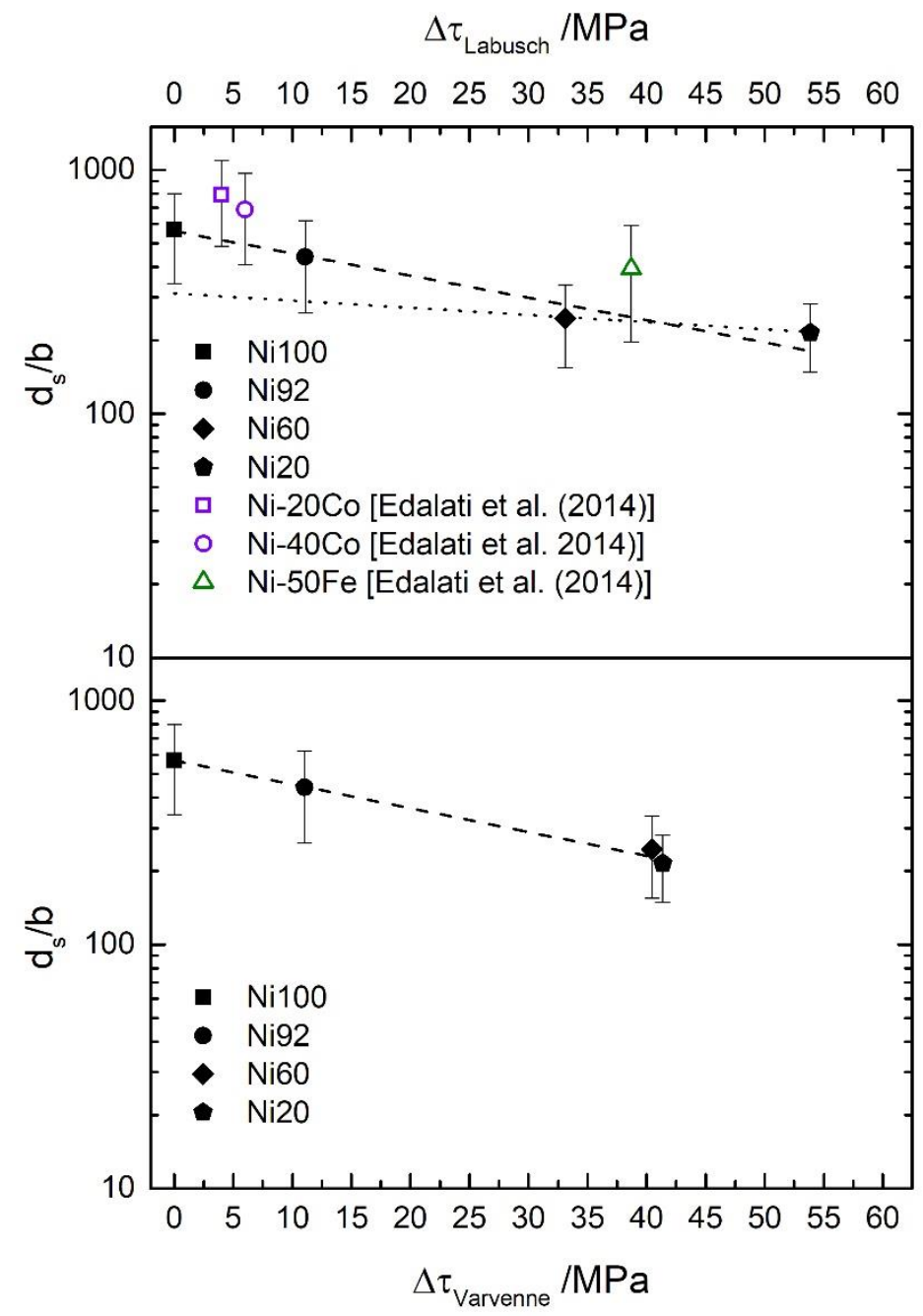

Fig. 4: Normalized grain size $d s / b$ as a function of the solid solution strengthening contribution $\Delta \tau$, determined by the Labusch 
Keil, T., Bruder, E., Laurent-Brocq, M., and Durst, K., From diluted solid solutions to high entropy alloys: Saturation grain size and mechanical properties after high pressure torsion. Scripta Materialia, 2021. 192: p. 43-48. https://doi.org/10.1016/j.scriptamat.2020.09.046

Tab. 1: Hardness $H$, indentation modulus $E$, strain rate sensitivity $m$, activation volume $V$, solid solution strengthening contribution $\Delta \tau$ according to the Labusch and the Varvenne model and saturation grain size $d_{s}$ of the different alloy compositions.

\begin{tabular}{|c|c|c|c|c|c|c|c|c|c|}
\hline \multirow{2}{*}{$\begin{array}{c}\text { Alloy } \\
\text { composition } \\
\text { /at.\% }\end{array}$} & \multicolumn{2}{|c|}{$\mathrm{H} / \mathrm{GPa}$} & \multicolumn{2}{|c|}{$\mathrm{E} / \mathrm{GPa}$} & \multicolumn{2}{|c|}{ SRJ } & \multirow{2}{*}{$\begin{array}{c}\Delta \tau_{\text {Varvenne }} \\
/ \mathrm{MPa}\end{array}$} & \multirow{2}{*}{$\begin{array}{c}\Delta \tau_{\text {Labusch }} \\
/ \mathrm{MPa}\end{array}$} & \multirow{2}{*}{$\begin{array}{l}\mathrm{d}_{\mathrm{s}} \\
/ \mathrm{nm}\end{array}$} \\
\hline & CG & HPT & CG & HPT & $\mathrm{m}$ & $V^{*} b^{3}$ & & & \\
\hline Ni100 & $\begin{array}{r}1.19 \\
\pm 0.1\end{array}$ & $\begin{array}{r}5.62 \\
\pm 0.2\end{array}$ & $\begin{array}{l}214.2 \\
\pm 8.3\end{array}$ & $\begin{array}{c}235.9 \pm \\
3.0\end{array}$ & $\begin{array}{c}0.012 \pm \\
0.001\end{array}$ & 21 & 0 & 0 & $\begin{array}{c}142 \pm \\
57\end{array}$ \\
\hline $\mathrm{Ni92}$ & $\begin{array}{r}1,51 \\
\pm 0.1\end{array}$ & $\begin{array}{r}5.88 \\
\pm 0.1\end{array}$ & $\begin{array}{r}216.4 \\
\pm 13.1\end{array}$ & $\begin{array}{c}233.9 \pm \\
2.5\end{array}$ & $\begin{array}{l}0.011 \pm \\
0,0014\end{array}$ & 22 & 11.03 & 11.10 & $\begin{array}{c}110 \pm \\
45\end{array}$ \\
\hline $\mathrm{Ni60}$ & $\begin{array}{r}1.98 \\
\pm 0.1\end{array}$ & $\begin{array}{r}6.52 \\
\pm 0.1\end{array}$ & $\begin{array}{l}193.1 \\
\pm 8.2\end{array}$ & $\begin{array}{c}206.5 \pm \\
3.9\end{array}$ & $\begin{array}{l}0.009 \pm \\
0,0008\end{array}$ & 23 & 40.45 & 33.13 & $62 \pm 23$ \\
\hline $\mathrm{Ni} 20$ & $\begin{array}{r}2.01 \\
\pm 0.1\end{array}$ & $\begin{array}{r}6.31 \\
\pm 0.1\end{array}$ & $\begin{array}{r}190.7 \\
\pm 8.3\end{array}$ & $\begin{array}{c}192.5 \pm \\
3.0\end{array}$ & $\begin{array}{l}0.011 \pm \\
0.0013\end{array}$ & 19 & 41.36 & 53.87 & $55 \pm 17$ \\
\hline
\end{tabular}


Keil, T., Bruder, E., Laurent-Brocq, M., and Durst, K., From diluted solid solutions to high entropy alloys: Saturation grain size and mechanical properties after high pressure torsion. Scripta Materialia, 2021. 192: p. 43-48. https://doi.org/10.1016/j.scriptamat.2020.09.046

In summary, the Cantor alloy and Ni-diluted subsystems were investigated with respect to saturation grain size, hardness and strain rate sensitivity to elucidate the evolution of these properties with composition from a pure element over a diluted solid solution up to the equiatomic HEA. For several mechanical properties like ISE and strain rate sensitivity no differences between HEA and diluted solid solutions were observed. All compositions exhibit a history dependent hardness in the SRJ tests, with Ni20 and Ni60 additionally showing yielding phenomena after the strain rate change to $0.001 \mathrm{~s}^{-1}$. The saturation grain size follows the empirical law proposed for binary solid solutions. Compositions with higher alloying content show higher SSS contributions according to the Labusch and Varvenne strengthening models and simultaneously smaller achievable saturation grain sizes by HPT deformation, thus, indicating a correlation between $d_{s}$ and $\Delta \tau$.

It is not mandatory to reach the equiatomic composition for an optimum of the mechanical properties. Ni60 exhibits approximately the same SSS contribution, same low saturation grain size and thus the same hardness compared to the equiatomic alloy (Ni20). Therefore, chemically complex systems beside the equiatomic composition and the transition from diluted systems to HEAs should be further investigated with respect to effects of solutes on dislocation dynamics. 
Keil, T., Bruder, E., Laurent-Brocq, M., and Durst, K., From diluted solid solutions to high entropy alloys: Saturation grain size and mechanical properties after high pressure torsion. Scripta Materialia, 2021. 192: p. 43-48. https://doi.org/10.1016/j.scriptamat.2020.09.046

Acknowledgements:

247 The authors gratefully acknowledge support by the German Research Foundation (DFG) under grant 248 number DU-424/13-1.

249

250 Conflicts of Interest:

251 The authors declare no conflict of interest.

252

253 Data availability:

254 The raw/processed data required to reproduce these findings cannot be shared at this time as the 255 data also forms part of an ongoing study. 
Keil, T., Bruder, E., Laurent-Brocq, M., and Durst, K., From diluted solid solutions to high entropy alloys: Saturation grain size and mechanical properties after high pressure torsion. Scripta Materialia, 2021. 192: p. 43-48. https://doi.org/10.1016/j.scriptamat.2020.09.046

References

1. Cantor, B., et al., Microstructural development in equiatomic multicomponent alloys. Materials Science and Engineering: A, 2004. 375-377: p. 213-218.

2. Miracle, D.B. and O.N. Senkov, A critical review of high entropy alloys and related concepts. Acta Materialia, 2017. 122: p. 448-511.

3. Yeh, J.-W., Alloy Design Strategies and Future Trends in High-Entropy Alloys. Jom, 2013. 65(12): p. 1759-1771.

4. Yeh, J.-W., et al., Nanostructured High-Entropy Alloys with Multiple Principal Elements Novel Alloy Design Concepts and Outcomes. Advanced Engineering Materials, 2004: p. 299-303.

5. Laurent-Brocq, M., et al., From diluted solid solutions to high entropy alloys: On the evolution of properties with composition of multi-components alloys. Materials Science and Engineering: A, 2017. 696: p. 228-235.

6. Bracq, G., et al., Combining experiments and modelling to explore the solid solution strengthening of high and medium entropy alloys. Acta Materialia, 2019.

7. Valiev, R.Z., et al., Producing bulk ultrafine-grained materials by severe plastic deformation. JOM, 2006. 58(4): p. 33-39.

8. Schuh, B., et al., Mechanical properties, microstructure and thermal stability of a nanocrystalline CoCrFeMnNi high-entropy alloy after severe plastic deformation. Acta Materialia, 2015. 96: p. 258-268.

9. Koch, C.C., Optimization of strength and ductility in nanocrystalline and ultrafine grained metals. Scripta Materialia, 2003. 49(7): p. 657-662.

10. Pippan, R., et al., Saturation of Fragmentation During Severe Plastic Deformation. Annual Review of Materials Research, 2010. 40(1): p. 319-343.

11. Edalati, K., et al., Influence of dislocation-solute atom interactions and stacking fault energy on grain size of single-phase alloys after severe plastic deformation using high-pressure torsion. Acta Materialia, 2014. 69: p. 68-77.

12. Bruder, E., et al., Influence of solute effects on the saturation grain size and rate sensitivity in Cu-X alloys. Scripta Materialia, 2018. 144: p. 5-8.

13. Kottke, J., et al., Tracer diffusion in the Ni-CoCrFeMn system: Transition from a dilute solid solution to a high entropy alloy. Scripta Materialia, 2019. 159: p. 94-98.

14. Glienke, M., et al., Grain boundary diffusion in CoCrFeMnNi high entropy alloy: Kinetic hints towards a phase decomposition. Acta Materialia, 2020. 195: p. 304-316.

15. Varvenne, C., A. Luque, and W.A. Curtin, Theory of strengthening in fcc high entropy alloys. Acta Materialia, 2016. 118: p. 164-176.

16. LaRosa, C.R., et al., Solid solution strengthening theories of high-entropy alloys. Materials Characterization, 2019. 151: p. 310-317.

17. Cardarelli, F., Materials Handbook. Vol. 2. 2008: Springer London.

18. Martienssen, W. and H. Warlimont, Springer Handbook of Condensed Matter and Materials Data. 2005: Springer Berlin Heidelberg.

19. Nix, W. and H. Gao, Indentation Size Effects In Crystalline Materials: A Law For Strain Gradient Plasticity. J. Mech. Phys. Solids, 1998. 46: p. 411-425.

20. Backes, B., et al., The correlation between the internal material length scale and the microstructure in nanoindentation experiments and simulations using the conventional mechanism-based strain gradient plasticity theory. Journal of Materials Research, 2009. 24(3): p. 1197-1207.

21. Otto, F., et al., The influences of temperature and microstructure on the tensile properties of a CoCrFeMnNi high-entropy alloy. Acta Materialia, 2013. 61(15): p. 5743-5755.

22. Skrotzki, W., et al., Microstructure, Texture, and Strength Development during High-Pressure Torsion of CrMnFeCoNi High-Entropy Alloy. Crystals, 2020. 10(4). 
Keil, T., Bruder, E., Laurent-Brocq, M., and Durst, K., From diluted solid solutions to high entropy alloys: Saturation grain size and mechanical properties after high pressure torsion. Scripta Materialia, 2021. 192: p. 43-48. https://doi.org/10.1016/j.scriptamat.2020.09.046

23. Zhilyaev, A.P., et al., Microhardness and microstructural evolution in pure nickel during highpressure torsion. Scripta Materialia, 2001. 44(12): p. 2753-2758.

24. Maier, V., et al., Nanoindentation strain-rate jump tests for determining the local strain-rate sensitivity in nanocrystalline Ni and ultrafine-grained Al. Journal of Materials Research, 2011. 26(11): p. 1421-1430.

25. Maier-Kiener, V., et al., Nanoindentation testing as a powerful screening tool for assessing phase stability of nanocrystalline high-entropy alloys. Materials \& Design, 2017. 115: p. 479485.

26. Schwaiger, R., et al., Some critical experiments on the strain-rate sensitivity of nanocrystalline nickel. Acta Materialia, 2003. 51(17): p. 5159-5172.

27. Wei, Q., et al., Effect of nanocrystalline and ultrafine grain sizes on the strain rate sensitivity and activation volume: fcc versus bcc metals. Materials Science and Engineering: A, 2004. 381(1-2): p. 71-79.

28. Monclús, M.A. and J.M. Molina-Aldareguia, High Temperature Nanomechanical Testing, in Handbook of Mechanics of Materials. 2018. p. 1-29.

29. Zhang, H.W., et al., Thermal behavior of $\mathrm{Ni}$ (99.967\% and $99.5 \%$ purity) deformed to an ultrahigh strain by high pressure torsion. Acta Materialia, 2010. 58(5): p. 1698-1707.

30. Varvenne, C. and W.A. Curtin, Predicting yield strengths of noble metal high entropy alloys. Scripta Materialia, 2018. 142: p. 92-95. 
Keil, T., Bruder, E., Laurent-Brocq, M., and Durst, K., From diluted solid solutions to high entropy alloys: Saturation grain size and mechanical properties after high pressure torsion. Scripta Materialia, 2021. 192: p. 43-48. https://doi.org/10.1016/j.scriptamat.2020.09.046

Appendix:

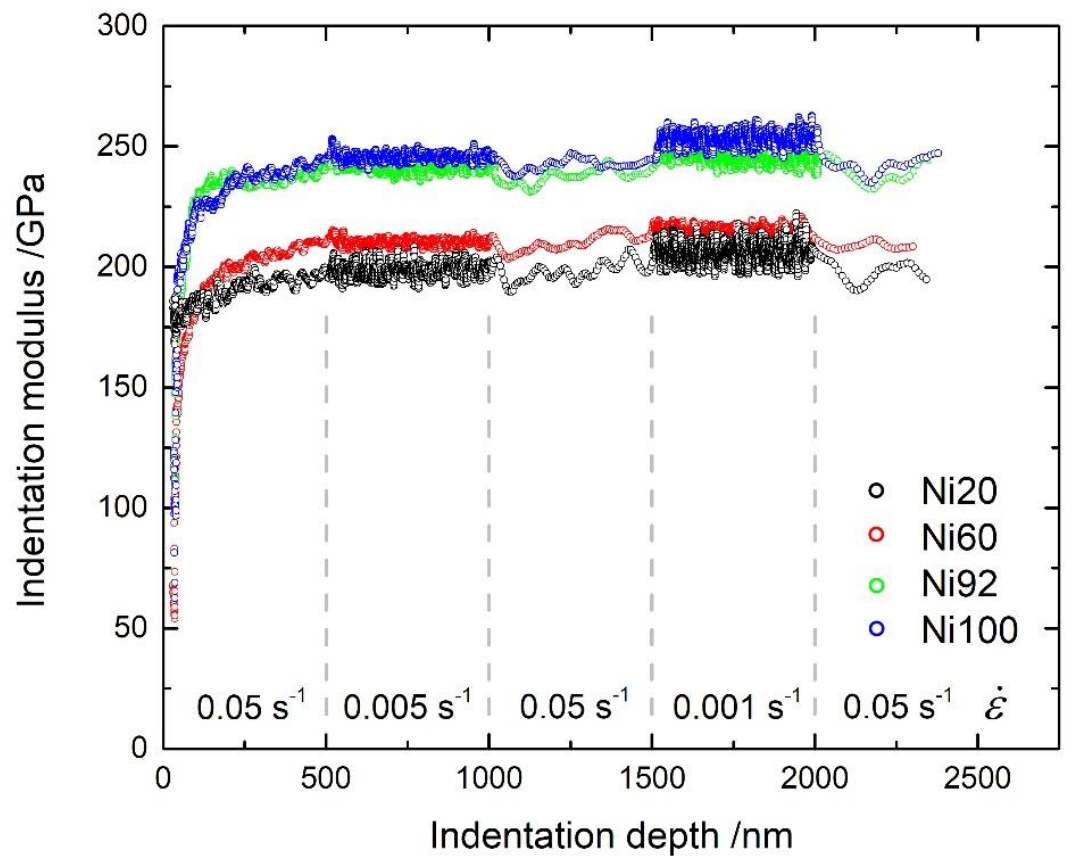

327

Appendix A1: Indentation modulus as a function of indentation depth for different strain rates of the deformed Ni-X HPT

329 samples. 
Keil, T., Bruder, E., Laurent-Brocq, M., and Durst, K., From diluted solid solutions to high entropy alloys: Saturation grain size and mechanical properties after high pressure torsion. Scripta Materialia, 2021. 192: p. 43-48. https://doi.org/10.1016/j.scriptamat.2020.09.046

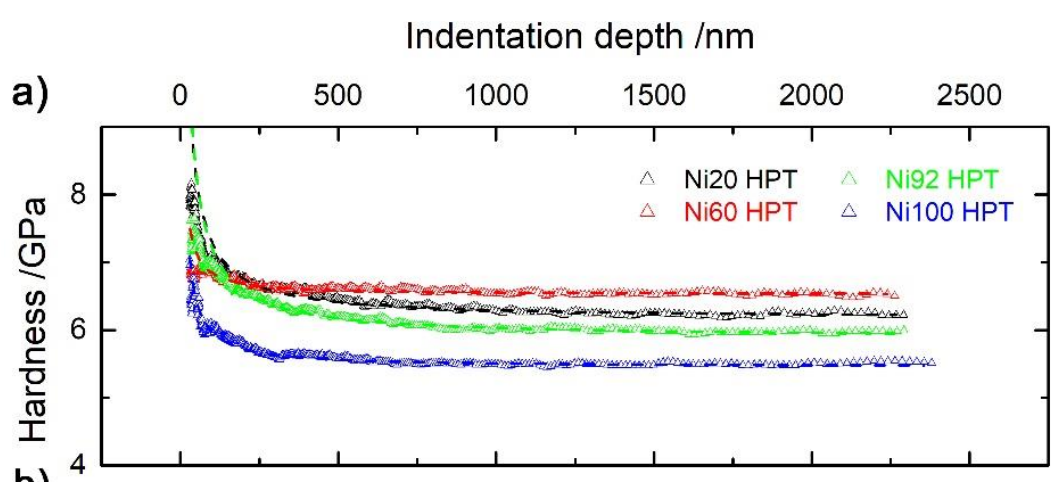

b)

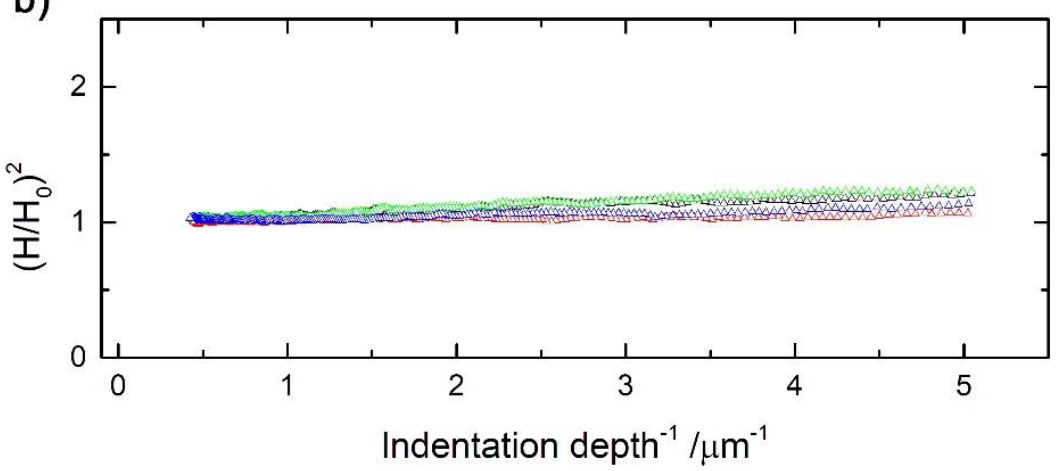

Appendix A2: Hardness as a function of indentation depth for the HPT samples at constant strain rate $\left(0.05 \mathrm{~s}^{-1}\right)$; the dashed lines represent the hardness calculated by the Nix-Gao model. 